\title{
SOME ASPECTS OF DERMATOLOGICAL CLINICAL TRIALS
}

\author{
E. Colin-Jones, M.B., B.S., F.P.S. \\ Dermatologist to Brighton, Tunbridge Wells and Chichester Group Hospitals
}

Glycyrrhetinic acid, a triterpene obtained from liquorice root, has a structure which bears some similarity to that of the corticosteroids. This sapogenin has been investigated pharmacologically and has been shown ${ }^{7}, 12$, il to be a potent antiinflammatory agent. A comprehensive veterinary trial ${ }^{14}$ using the double blind technique showed that glycyrrhetinic acid (branded Biosone G.A.) was effective in the treatment of many inflammatory skin and other conditions in dogs. It has also been shown to be of great value in the treatment of inflammatory conditions of the oral cavity. ${ }^{8}$ Dermatologically, its effect in the treatment of eczematous and other lesions has been reported. ${ }^{2,3,4,6, ~ 9, ~ 13, ~} 15$

In April 1959, ${ }^{1}$ the British Medical fournal gave a short review of some of the published clinical work on glycyrrhetinic acid ointments, quoting references to a number of favourable and unfavourable reports on the efficacy of this preparation. It was suggested that this inconsistency may have been due to a variety of reasons, such as the planning of the controlled experiments, the selection of control subjects and also the fact that all substances called glycyrrhetinic acid may not be identical. It also stated that it was impossible to be certain of the merits, if any, of glycyrrhetinic acid in dermatology and suggested that 'further properly designed investigations' were still required before the various preparations could be recommended for routine use or discarded as ineffective. Possibly the most sober appraisal of the whole controversy was made by Sommerville, ${ }^{17}$ who stated 'there has been an almost unseemly rush to be in at the death of a new drug.'

Although the trials of Colin-Jones and Somers, ${ }^{4}$ covering 254 cases, and Evans, ${ }^{6}$ I 24 cases, would appear conclusive, they have been criticized because the double blind technique was used in only a small number of cases.

At the suggestion of Professor Stanley Alstead of the Department of Materia Medica and Therapeutics, Glasgow University, it was agreed to institute a tripartite double blind controlled trial of glycyrrhetinic acid ointment (Biosone G.A. brand) against inert base in certain skin con- ditions. The purpose of the trial was to find out whether the results of the previous trial ${ }^{4}$ could be confirmed, using larger numbers of cases with three independent clinicians taking part. The three dermatologists were Dr. A. Girdwood Fergusson of Stobhill Hospital, Glasgow (at the suggestion of Professor Alstead), Dr. D. S. Wilkinson of the Royal Buckinghamshire Hospital, Aylesbury, and Dr. E. Colin-Jones of Royal Sussex County, Royal West Sussex and Kent and Sussex Hospitals. Dr. Fergusson had no previous experience of Biosone G.A. ointments, Dr. Wilkinson had some little experience, and Dr. Colin-Jones had used these preparations for over three years.

The trial was arranged in a statistically planned manner by the double blind technique, where neither the clinician nor the patient would know the type of ointment used.

The preparations under trial consisted of an ointment containing $2 \%$. Biosone G.A. bran glycyrrhetinic acid in a non-greasy base and the inert base. These preparations were prepared and supplied by Dr. S. Gottfried of Biorex Laboratories Ltd., in tubes and were labelled 'Dermatological Ointment,' numbered in a randomized manner and the key to the identities supplied in sealed envelopes to the clinicians. Each clinician received identical sets of tubes and codes.

As Professor Alstead suggested that this trial was to be a 'repetition' of the previous trial, the dermatologists were given the criteria of that original trial: Adult patients with a suitable I.Q. were to be carefully selected, the selection to be of conditions with eczematous patterns of dermatitis, with the eczema extending at least over both arms or both legs, such lesions to be symmetrical both in size and in intensity. Selection was to exclude self-resolving lesions and cases were to be chosen in which conventional therapy would be expected to produce equal benefit on both lesions. A reprint of the original article ${ }^{4}$ was sent to each dermatologist to give him a general idea of the conditions where the drug had been shown to be effective. All patients were to be seen by the dermatologist, their intelligence assessed and what was required of them clearly explained. Two 
tubes of ointment labelled $\mathrm{L}$ and $\mathrm{R}$ and numbered were to be given to each patient with instructions to apply them to the respective side of the body twice daily in equal quantities. The treatment was to last for I 4 days, the patients were to be seen weekly and objective and subjective observations to be noted; final assessment was to be made objectively. Any patients deviating from any of the conditions of the trial were to be excluded. At the conclusion, the individual trials and the combined results were to be assessed statistically.

However, each dermatologist had his own views on the conduct of the trial and the manner of selection of cases. Dr. Fergusson decided that in his trial there would be no selection or rejection of patients, except that they would all be suffering from symmetrical eczematous conditions. Dr. Wilkinson preferred to use unselected cases, except that (I) their skin condition was to be symmetrically distributed and roughly equal on both sides; (2) their intelligence was to be regarded as sufficient to give an opinion on the two ointments (i.e. mental defectives and children were to be excluded); and (3) certain conditions only were to be included: eczema, acute, subacute and chronic, lichen simplex, contact dermatitis and a few cases of other types. Dr. Colin-Jones, on the other hand, wished to carry out the evaluation according to the criteria of the original trial as agreed with Professor Alstead.

The results of the respective trials are now described individually.

\section{A. Trial by Dr. A. Girdwood Fergusson.}

The cases treated were as follows:

Infectious eczematoid dermatitis . 8 cases

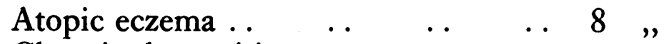

Chronic dermatitis venenata .. $\quad . .7 \%$,

Neurodermatitis .. . . . 2 ,"

The results (Tables $I$ and 2) show that in 14 out of 25 cases there was no difference between the ointment and base. The number of placebo reactors was high, $52 \%$ of the cases responding to the base alone, although none of the 25 cases were 'self-resolving.' Indeed, every one of them required a considerable amount of treatment on conventional lines at the end of the two weeks' period of trial and a number are still attending for treatment (ten months later). The cases which showed improvement on either the ointment or base did so during the 14 days, but in many this improvement was not maintained and conventional methods were required; in some, remission and relapse has persisted despite all forms of treatment. It is interesting to note that in the two cases of neurodermatitis, a condition which has previously been reported ${ }^{4,6}$ to be responsive
TABLE I



Statistical analysis of Table 2-improved against not improved: $\chi^{2}=3.125, \mathrm{n}=1,0.10>\mathrm{P}>0.05$.

to this particular form of therapy, the ointment was superior to the base.

B. Trial by Dr. D. S. Wilkinson.

Here the following cases were treated:

Eczema-dermatitis, acute and sub-

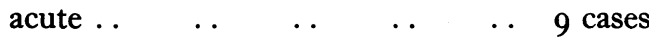

Eczema, chronic and atopic .. $\quad . .96 \%$

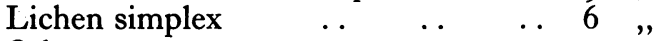

$\begin{array}{lllllll}\text { Other } & \ldots & \ldots & \ldots & \ldots & \ldots & 3\end{array}$

The results of the trial (Tables 3 and 4 ) show the difference between the ointment and base to be significant. During the course of the trial, out of interest, four cases (pruritus ani, etc.) were in cluded where treatment had to be given consecutively. Although there was no reason to think that four cases treated in sequence differo in principle in their response (each ointment was given first on two occasions as it happens), these cases were eliminated in the combined statistics of the three trials. The results were graded and where the differences were slight and the effect doubtful, these were counted as ' not improved.' Analysis of the cases showed that in acute conditions there was no bias in favour of the ointment, but in the remaining conditions the ointment appeared to be better than the control base.

C. Trial by Dr. E. Colin-fones.

The cases treated were:

$\begin{array}{llllll}\text { Erythroderma. . } & \ldots & \ldots & \ldots & \text { I case }\end{array}$

Table 3

\begin{tabular}{c|c|c|c}
\hline Total & $\begin{array}{c}\text { Ointment } \\
\text { Better Than } \\
\text { Base }\end{array}$ & $\begin{array}{c}\text { No } \\
\text { Difference }\end{array}$ & $\begin{array}{c}\text { Ointment } \\
\text { Worse Than } \\
\text { Base }\end{array}$ \\
\hline 27 & 11 & 14 & 2 \\
\hline
\end{tabular}

\begin{tabular}{|c|c|c|}
\hline & Improved & Not Improved \\
\hline $\begin{array}{l}\text { Ointment alone } \\
\text { Base alone } \quad . .\end{array}$ & $\begin{array}{r}17 \\
8\end{array}$ & $\begin{array}{l}10 \\
19\end{array}$ \\
\hline
\end{tabular}

Statistical analysis of Table $4: \chi^{2}=6.03, n=1$, $0.02>\mathrm{P}>0.01$. 
TABLE 5

\begin{tabular}{c|c|c|c}
\hline Total & $\begin{array}{c}\text { Ointment } \\
\text { Better Than } \\
\text { Base }\end{array}$ & $\begin{array}{c}\text { No } \\
\text { Difference }\end{array}$ & $\begin{array}{c}\text { Ointment } \\
\text { Worse Than } \\
\text { Base }\end{array}$ \\
\hline 25 & 17 & 4 & 4 \\
\hline
\end{tabular}

Table 6

\begin{tabular}{l|c|c|c}
\hline & Improved & $\begin{array}{c}\text { Little or No } \\
\text { Improvement }\end{array}$ & Worse \\
\hline $\begin{array}{l}\text { Ointment alone } \\
\text { Base alone }\end{array}$ & 21 & - & 4 \\
\hline
\end{tabular}

Statistical analysis of Table 6 -improved against not improved: $\chi^{2}=25.12, \mathrm{n}=1, \mathrm{P}<0.001$.

Contact dermatitis . . $\quad$. . $\quad$.. 2 cases

Chronic eczema $\quad$. $\quad \ldots \quad$. 303 ,

Eczema (seborrhoeic factor in 2) . 16 ,

Neurodermatitis . . . . . 3 , 3 ,

In this trial the difference between ointment and base is highly significant (Tables 5 and 6). The selection of the cases for this trial was made most carefully. All pompholyx reactions were excluded as these are so often the result of sensitization, as, for example, fungus infections of feet producing pompholyx reaction on hands, contact irritants such as coolant oils, detergents which also sensitize the skin and prevent rapid response, eruptions associated with moisi lesions, which not only make the local use of this ointment unsuitable but also produce a sensitivity reaction. The cases were chosen from conditions where there was localized thickening of the skin, evidence of much rubbing, symmetrical dry eczematous reactions (tending to be configurate rather than nummular), psoriasiform eczema, erythroderma and pruritus associated with reticuloses. The conditions laid down were strictly adhered to in this trial. Patients for the main part had suffered from the conditions for varying periods, having passed from the acute to the subacute or chronic phase of their disorders. The patients were seen at weekly intervals and the effect of treatment assessed on a combination of subjective and symptomatic improvement. All patients were instructed not to wash, to avoid soap and water and rubber gloves next to the skin.

\section{Combined Results.}

The combined results of the three trials are shown in Tables 7 and 8 , with the omission in the case of Dr. Wilkinson's trial of the four cases treated consecutively. If we exclude the cases in which the observer recorded no difference, we find that treatment with the Biosone G.A. ointment was superior to that with inert base in 33 cases out of 42 . This difference is highly significant $(P<0.001)$. Statistically, the results ob-
TABle 7

\begin{tabular}{l|c|c|c|c}
\hline Observer & $\begin{array}{c}\text { Ointment } \\
\text { Better } \\
\text { Than } \\
\text { Control }\end{array}$ & $\begin{array}{c}\text { No } \\
\text { Differ- } \\
\text { ence }\end{array}$ & $\begin{array}{c}\text { Control } \\
\text { Better } \\
\text { Than } \\
\text { Biosone }\end{array}$ & $\begin{array}{c}\text { Total } \\
\text { Cases }\end{array}$ \\
\hline Dr. F. $\quad .$. & 8 & 14 & 3 & 25 \\
Dr. W. . . & 8 & 13 & 2 & 23 \\
Dr. C. J. . . & 17 & 4 & 4 & 25 \\
All observers & 33 & 31 & 9 & 73 \\
\hline
\end{tabular}

TABLE 8

\begin{tabular}{|c|c|c|c|}
\hline & & Improved & $\begin{array}{l}\text { Little or No } \\
\text { Improvement } \\
\text { or Worse }\end{array}$ \\
\hline $\begin{array}{l}\text { Ointment alone } \\
\text { Base alone } \quad .\end{array}$ & $\begin{array}{l}\ldots \\
\ldots\end{array}$ & $\begin{array}{l}54 \\
25\end{array}$ & $\begin{array}{l}19 \\
48\end{array}$ \\
\hline
\end{tabular}

Statistical analysis of Table 8-improved against others: $\chi^{2}=23.2, \mathrm{n}=1, \mathrm{P}=<0.001$.

tained by the three observers are similar, the difference between them being quite insignificant (P>0.8).

While it may be argued that the cases in which no difference was recorded are important and should not be omitted from consideration, it is perfectly proper to make a statistical comparison of the number of cases improved by the two methods of treatment. Clearly, if there were a very large number of cases in which no difference was recorded the advantage attributed to the trial drug would not be clinically very important, but these cases do not invalidate the conclusion that there is a statistically significant difference between the results obtained with the two substances. It should be noted that the proportion of ' no difference' cases recorded by the three observers was different and that these differences are too large to be easily attributed to chance. A $\chi^{2}$ test applied to the figures in Table 7 gives $\chi^{2}=11.20$, $\mathrm{n}=4, \mathrm{P}=0.02$. There are two possible explanations for these discrepancies, either (I) the observer allowed smaller differences to qualify as indicating that one substance was preferable to the other, or (2) one observer selected patients for the trial which were more likely to respond to the special treatment.

\section{Discussion}

Although the results of the three individual trials appear to differ, it has been shown statistically that, by the elimination of cases which responded equally to ointment and base, the differences between the three trials were insignificant. All three dermatologists are agreed that there was definite evidence in favour of Biosone G.A. ointment in chronic skin conditions such as neurodermatitis. Dr. Colin-Jones and Dr. Wil- 
kinson found also evidence in favour of the ointment in the treatment of pruritic conditions.

Variations were made by the individual dermatologists in the planning of the trial, the selection of cases and the selection of patients with regard to their I.Q., all factors which can influence the results of a trial.

The varying results of this trial seem undoubtedly to be due to the selection of cases and obviously this has been influenced by the experience or lack of experience with the drug of the clinicians taking part. Dr. Colin-Jones, having used this drug for over three years, has been able to make a critical selection of cases which would be most likely to respond and this would seem to reflect most accurately the value of the drug.

In the group treated by Dr. Fergusson it was found that 13 cases out of 25 responded to the base alone. These results are similar to those reported by Schamberg, Askovitz and Greenberg ${ }^{16}$ where a large series of 5 ro consecutive cases of unselected inflammatory dermatoses were treated with various corticosteroid preparations and compared with inert base. The authors have concluded that the corticosteroid ointments were no better than the placebo, two of the explanations being given that many of the patients were placebo reactors and also that there was a large percentage of patients $(54.8 \%)$ in whom the two were equal in effect. Kennedy ${ }^{10}$ has stated that 'There is no reliable way of detecting the placebo-reactor in advance. ... The effect of his inclusion in largescale experiments is to lower the sensitivity, to dilute the success of a new drug so that its effects may not appear significant. . . An editorial in the Fournal of the American Medical Association ${ }^{5}$ states: 'A large number of (placebo) reactors in the control series (of a double-blind test) would tend to decrease the difference between the results obtained with a potent and valuable drug and the controls, possibly to the point of indicating that the drug is worthless.'

The double-blind technique and the use of placebo controls are now accepted practices in clinical trials. However, this trial brings out a number of further important features in the design of a dermatological clinical trial aimed at the assessment of the value or otherwise of a drug. Initial experience with the drug has been shown to be of the first importance as, by excluding from the trial conditions in which experience has shown it is not likely to be effective, a truer assessment is likely to be made as to whether or not the drug is effective at all. The intelligence of the patient is important as even in such a simple procedure as using two ointments on different parts of the body, confusion can very easily creep in. The degree of co-operation by the patient is therefore a vital factor in the success or otherwise of the trial. Wherever possible the patient should act aso his own control, preferably by the use of the symmetrical lesion technique. It has been stated ${ }^{18} \mathrm{Q}$ that 'the results of such uniform, symmetrical,,$\cdot$ simultaneous, paired comparison tests conducted $\vec{\Rightarrow}$ in six men are as valid as an experiment using 50 men in whom non-symmetrical lesions are treated in rotation.'

\section{Summary}

The results of a tripartite double-blind controlled trial of Biosone G.A. brand glycyrrhetinic $\vec{O}$ acid ointment against inert base are described. $\vec{\overrightarrow{ }}$ The statistical analyses of the individual trials and $\mathrm{o}^{\circ}$ the combined results are given and discussed.D All three dermatologists agreed that the drug has 3 a therapeutic value in certain dermatoses particu-i. larly of the chronic type. The trial illustrates also? the importance of some previous experience in $\vec{N}$ using the drug and the importance of selection of ${ }_{-}^{-}$ cases where an 'optimal' response may be anticipated.

\section{Acknowledgments}

I am indebted to Professor Stanley Alstead for his help in initiating this trial and all the advice 3 and guidance given, Dr. A. Girdwood Fergussơn and Dr. D. S. Wilkinson for partaking in the trial, allowing me to publish their results and the help given in the preparation of this paper, B⿳亠丷厂. Richard Doll for advice and statistical interpretation of the results, and Dr. S. Gottfried of Biorex Laboratories Ltd. for his assistance andō supply of material.

REFERENCES
Annotatio.1:3 (1959), 'Glycyrrhetinic Acid Ointment,' Brit. med. F., i, 914 .

2. CAVALIERI, R. (1958), Cron. Ist derm. Immac. (Roma), July-August, 142.

3. COHEIN, E. LIPMAN (1958), Practitioner, 181, 618.

4. COJ_IN-JONEs. E., and SOMERS, G. F. (1957), Med. Press, 238, 206.

5. Editcrial (1955), 'Placebos,' 7. Amer. med. Ass., 159, 780.

6. EVANS, Q. F. (1958), Brit. F. clin. Pract., 12, 69.

7. FINNEY, R. S. H., and SOMERS, G. F. (1958), f. Pharm. ( I sid.), I0, 6r3.

8. FRY, SIR W. K., and GOLDMAN, V. (1958), Brit. Dent. $¥ .$, IC4, 55 .

9. ITO, K., and KURODA, K. (1955), Bull. pharmac. Res. Inst 9, 30 .

10. KENNEDY, A. (1959), Pharm. F., 1, 23.

I I. KRAUS, S. D. (1959), The Physiol., $2,72$.

12. LOGEMANN, W., LAURIA, F., and TOSOLINI, G. (1957), హె Chem. Ber., 90, 601.

13. MACKENNA, R. M. B. (1959), Brit. med. F., ii, 1244.

14. PHILLIPS, A. P., and SOMERS, G. F. (1958), Vet. Rec. $\mathrm{N}$ 70, 799.

1 5. POZZO, G. (1957), G. ital. Derm. Sif., 98, r9r.

16. SCHAMHERG, I. L., ASKOVITZ, S. I., and GREENBERG, M. (1958), A.M.A. Arch. Derm., 78, 490.

17. SOMMERVILLE, J. (1957), Brit. med. F., i, 282.

18. SULZBERGER, M. B., BAER, R. L., KANOF, A., and LOWENBERG, C. (1946), $\boldsymbol{F}$. invest. Derm., 7, 227. 